\title{
A escrita teatral ${ }^{1}$
}

\section{Theatrical writing}

Philippe Minyana ${ }^{2}$

Tradução: W. Anthony Alano ${ }^{3}$ e Stephan Arnulf Baumgärtel ${ }^{4}$ 


\section{Resumo}

Três grandes períodos são marcantes no teatro de Philippe Minyana: os anos 1980 com a importância aferida à logorreia, ao maximalismo e ao monólogo; os anos $1990 \mathrm{com}$ a passagem ao minimalismo e o surgimento do fragmento, do segmento; e enfim os anos 2000 com o retorno ao nome próprio e um mergulho no surreal. É toda sua concepção da escrita teatral que é definida pela importância acordada à forma e às possibilidades de mudança de formato da narrativa.

Palavras-chave: Escrita teatral contemporânea; estrutura monológica; material cotidiano; minimalismo; escrita teatral autobiográfica.

\section{Abstract}

In this essay, Phillipe Minyana situates his work as a playwright within three historical moments, i.e., the 80 s, the $90 \mathrm{~s}$ and contemporary playwriting, respectively. Whereas in the $80 \mathrm{~s}$, the main formal and thematical influence on his writing is the monologue and material taken from quotidien fait divers, in the 90 s fragmentation of plot and character comes to the front. Finally, from 2000 onwards, que question of the real, writing in one's own name, as well as surreal structures play an important role in his practical exerimentations on form and narrative structure within playwriting.

Keywords: Contemporary playwriting; monologic structure; quotidien material; minimalism; autobiographical playwriting.

ISSN: 1414.5731

E-ISSN: 2358.6958
${ }^{1}$ Texto originalmente publicado como L'ecrit na Revista Persee, vol. 83, número 83,2008 , p.115-122

2 Philippe Minyana nasceu em 1946, em Besançon (FR). Escreveu mais de trinta obras desde 1979. Ator, diretor e dramaturgo francês com inúmeras obras publicadas e encenadas. Escreve também libretos de ópera.
${ }^{3}$ Mestrando em Teatro pelo PPGT/CEART-UDESC. Servidor da UDESC.

4 Professor Dr. Associado da Universidade do Estado de Santa Catarina (UDESC), atuando junto ao Programa de Pós-Graduação em Teatro (PPGTCEART). stephao08@yahoo.com.br 


\section{A questão da especificidade da escrita teatral contemporânea}

A especificidade da escrita dramática contemporânea depende de diversos fatores. Antes de mais nada, o herói desapareceu e as personagens tornaram-se figuras anônimas familiares e ordinárias que se assemelham a cada um de nós ${ }^{5}$. São personagens portadoras de nomes genéricos tais como Um, Dois, ou O Pai, A Mãe, ou ainda O Pequeno Homem, A Mulher Alta. Forma-se assim uma polifonia de vozes sonantes, que são reais e coerentes.

Por outro lado, tudo se passa em lugares íntimos: salões, quartos, escritórios e todos os lugares de trabalho ou de vida. E por fim, a língua, que adquire uma importância primordial: ela é ação e ela é música. Em todos os países do mundo pode-se observar esse trabalho sobre a língua e a prioridade que the é concedida, mas isso não significa que o sentido ou a ficção sejam esvaziados. Essa importância que é concedida à língua musical, à língua escrita, à língua trabalhada, que é por si só uma ação, encontra-se em Thomas Bernhard ou em Herbert Achternbusch.

Os temas da escrita contemporânea, além disso, são os temas eternos que existem desde o início do teatro. Encontramos aqui os conflitos, a paixão amorosa, o ciúme, o trabalho, o assassinato...

Meu projeto de escrita se aproxima do trabalho de certos autores como Noëlle Renaud, no sentido em que ela trabalha igualmente com a forma, com a língua e o humor. Me sinto próximo de sua investigação a cerca dos "formatos", formatos que não são aqueles habitualmente utilizados em uma peça de teatro clássico, com cenas e uma progressão. Os formatos que ela utiliza são mesclas de conto, poema e teatro e eles conferem um outro dispositivo à palavra.

Meu projeto teatral se aproxima também de um autor como Jean-Luc Lagarce, autor que conta a grande história fundamental, a história-matriz da família, da origem, do país, o país de onde nós viemos e para onde retornamos. Reencontramos as grandes mitologias contemporâneas presentes no teatro, como a relação pais e filhos, a reconciliação, os reencontros, a volta, a expectativa da morte. No final das contas, no caso de todos esses autores, não aborda-se o sujeito, pois a escolha de um sujeito reduz o campo das ações e o projeto de cultura. Ou seja, existindo um projeto de escrita teatral, este pode ter certas constantes como as figuras falantes, às quais se inserem os grandes e eternos temas da literatura. Uma peça de teatro não se reduz a um encadeamento de réplicas, a um pingue-pongue verbal. Já Michel Vinaver, nos anos setenta, deixou isso claro quando usou um sistema de trançagem das falas, criando uma polifonia ${ }^{6}$. Age-se assim como se fosse tudo real, pois é constituído de amostras do real, de efeitos de realidade. Ora, a conversação é feita de trançados, de cruzamentos. O que nos fascina é essa mistura e proximidade das falas que conferem

\footnotetext{
5 Sobre a desaparição do personagem no teatro contemporâneo, ler a obra de Robert Abirached, La Crise du personage dans le théâtre contemporain, Paris, Gallimard, 1978, assim como as análises de Jean-Pierre Ryngaert e Julie Sermon sobre o surgimento do termo "figura" em Le Personage théâtral contemporain: décomposition, récomposition, Paris, Éditions théâtrales, 2006 , p. $10 \mathrm{sq}$.

${ }^{6}$ Sobre a "trançagem das falas" de Vinaver, ler o artigo de Jean-Pierre Ryn-
}

gaert, « Jouer le texte en éclats : l'acteur et le théâtre de Michel Vinaver », in Wilfried Floeck (dir.), Zeitgenössisches theater in Deutschland und Frankreich - Théâtre contemporain en Allemagne et en France, Tübingen, Francke Verlag, 1989, p. 221 sq. 0 artigo de Irène Sadowska-Guillon, « Le "théâtre limite" de Philippe Minyana » (L'Avant-Scène Théâtre, $\left.n^{\circ} 748,1987\right)$ trata da influencia de Michel Vinaver sobre a escrita de Philippe Minyana. 
algo vivo, algo real. Não se procura reproduzir esse sistema da palavra múltipla, mas antes reinventá-lo ou reconstituí-lo. Fala-se então de partitura, de organização, de música e de polifonia.

Dentro desse contexto desenrola-se um verdadeiro progresso: durante os anos setenta e oitenta evocou-se a ausência de autores ao passo que hoje parece haver muitos. Todo mundo escreve, e o que faz o diferencial na França é a variedade das escritas. Enquanto que na Alemanha, no Québec e na Inglaterra existem escolas de escrita teatral, não é este o caso na França. Apesar disso, é necessário mencionar a escola da Rue Blanche em Lyon, na qual Enzo Cormann mantém uma oficina de abordagem da escrita teatral. O que existe na França é uma inteligência da escrita teatral contemporânea difundida e transmitida graças ao trabalho de universitários, de professores dos cursos de letras e teatro; são oficinas, debates, autores que se manifestam após uma peça, estágios, seminários e conferências, assim como todas as leituras dramáticas que eles organizam e nas quais também participam. Isso proporciona uma abertura real ao vivo, ainda que o vivo cause medo.

\section{O lugar do monólogo nas peças dos anos 80}

A ideia do monólogo nasceu do choque pelo qual passei ao ler Herbert Achternbusch, um autor de teatro. Ele utilizou esse sistema de enunciação com uma personagem única, com solos endereçados a uma pessoa que não diz nada ou pouca coisa. É um pouco também um princípio que será retomado por Thomas Bernhard mais tarde. São histórias verdadeiras, histórias de gente que realmente existiu, com essa fala caótica, doente, incorreta, essa fala de todos os dias chamada 'popular'. Os autores fizeram disso partituras fabulosas para os atores e os diretores.

Depois do choque com Achternbusch, eu me empenhei em folhear os faits divers $^{7}$ do jornal Libération que eu selecionara, e me dei conta que nesses jornais havia grandes mágoas e grandes cantos de tristeza ou de massacres. As Medeias ou Antígonas se chamam hoje Arlette ou Monique: elas se vingam, matam suas crianças, são ciumentas, estão sozinhas e irão se suicidar. Elas se tornam desta feita os eternos e universais arquétipos humanos. De imediato, pareceu-me interessante fazer com que elas se cruzassem e talvez respondessem uma à outra, e compus seis monólogos com temas recorrentes como a mãe, o país, o território, o luto, a alegria, o sofrimento, com efeitos da realidade constante. Isso trouxe o prazer da logorréia, da verborragia, da abundância, do maximalismo. Fazer alguém falar e que isso soe verdadeiro chega a me causar vertigens. Em consequencia, formou-se esse sistema da logorréia, da confissão longa e detalhada, com o qual escrevi muitas de minhas peças nos anos 80, como Inventaires, Chambres, Les Guerriers e Où vas-tu Jêrémie?8

\footnotetext{
7 Faits divers, literalmente "fatos diversos", são o equivalente às notas e reportagens que encontramos nas seções "Geral" dos jornais brasileiros e se caracterizam por apresentarem casos inexplicáveis, excepcionais, pitorescos. Em geral são acontecimentos trágicos, como crimes, acidentes ou delitos, descritos em poucas linhas (N.T.).

8 Philippe Minyana, Inventaires, Paris, L'Avant-scène, nº 809, 1987 ; reelabo-
}

rado em uma versão ligeiramente diferente nas Éditions théâtrales em 1993. Chambres, Paris, Éditions théâtrales / Edilig, 1988 ; reeditado nas Éditions théâtrales em 1993. Les Guerriers, Paris, Éditions théâtrales /Edilig, 1988 ; reeditado nas Éditions théâtrales em 1993. Où vas-tu Jérémie ?, Paris, Éditions Théâtrales, 1989. 
Hoje eu tenho tendência a preferir o "oratório" ao monólogo, porque nele existe a possibilidade de uma espécie de perversão do monologo. Todo mundo escreve seu monologo sobre a morte de sua mãe ou o câncer do pai e a utilização do monologo empobreceu o ato teatral e a presença em cena. Não quero parecer arrogante, mas freqüentemente isso gera decepção. Eu digo "oratório", mas trata-se de uma palavra prática. $O$ oratório tem a pretensão de ser poético ${ }^{9}$, e necessita um esforço de orquestração e de enquadramento da palavra.

Isso significa que é preciso orquestrar os monólogos juntos, fazer deles uma partitura que se torna um projeto artístico e não um projeto sociológico (ou psicológico). Não se trata de ter compaixão por essa pobres mulheres que matam o seu filho porque não podem criá-lo, mas fazer disso figuras teatrais explícitas. Aqui, a ficção acode novamente, mas ela precisa de organização, ela tem necessidade de um língua muito trabalhada, de uma arte.

A escrita é para mim um laboratório permanente. A escrita, dessa forma, se abre amplamente para o teatro e pode-se fazer então todo tipo de mestiçagem, isto é, trabalhar sobre o conceito de narrativa. Às vezes a narrativa pode substituir a didascália. Às vezes, apenas a margem esquerda da pagina é preenchida com uma série de segmentos empilhados que se formam como falsos versos. Nesse sentido, há um trabalho sofisticado sobre a palavra pronunciada pelos atores. Dei-me conta de que poderia-se chamar de "palavra segunda" essa palavra organizada, ruminada, redita: é como se as pessoas já a tivessem pronunciado. Esta palavra é mais refinada, mais refletida, e se opõe à palavra primeira da logorréia, a qual é a palavra da confissão orgânica.

Utilizo também citações que furto de alguns autores, aprecio essas frases que me entusiasmam e me alimentam. Eu as tomo emprestadas, as sedimento e dou-lhes sintaxe. Existe nisso uma arquitetura, é como se fosse a partitura dos músicos ${ }^{10}$. Tudo é preparado de antemão, eu me abasteço de palavras ouvidas, de nomes próprios, de sobrenomes, de fragmentos de frases. Há também o trabalho prévio em cadernetas, cadernos, e enfim, há o ato de escrever. Sou especialmente consciente disso, talvez porque eu escrevo à mão e passo a limpo.

Eu finalizo atualmente a peça Sous les arbres. Ela tinha uma centena de páginas no inicio e enchia três cadernos. Passei-a a limpo com a minha caneta sobre a resma de folhas brancas: a peça se estendia por 82 paginas e eu disse a mim mesmo que aquilo ainda não era satisfatório. Rescrevi-a uma terceira vez e restaram apenas 36 páginas, porque o trabalho havia sido limpo, eviscerado de tudo o que parecesse impreciso e que não respeitasse meu projeto inicial de que a peça fora como um canto épico, uma canção de gesta, o relato de uma epopéia, de uma errância de dois meninos que vagam de lugar em lugar. Aliás o tema da errância e do périplo é uma velha matriz literária e aprecio muito essa matriz. Ou seja, se quero respeitar minha canção de gesta, meu poema pelo menos precisa de muita economia e em vista disso

\footnotetext{
${ }^{9}$ Philipe Minyana, « Je suis contre le monologue », in Le Monologue au théâtre (1950-2000). La parole solitaire, Dijon, Éditions universitaires, 2006, p. 15 sq. $(1950-2000)$. La parole solitaire, Dijon, Editions universitaires, 2006, p. $15 \mathrm{sq}$.
${ }^{10}$ Nesse sentido pode-se ver o filme documentário de Jérôme Descamps, La
}

Secrète Architecture du paragraphe. Rencontre avec Philippe Minyana, Paris, 
ele fica reduzido.

Existe para mim a escrita antes de tudo porque haverá um tablado de teatro para ela; porque haverá a sua encarnação pelos atores que eu conheço, por atores específicos para os quais eu escrevi. Consequentemente, existe uma colaboração ardente entre os futuros intérpretes: eles já estão em mim antes de estarem sobre o palco e então, quando eles chegam realmente sobre o tablado, é mágico e milagroso. O acontecimento faz viver uma coisa maravilhosa. Minha escrita é destinada a ser dita, pronunciada, proferida no espaço do teatro.

Entretanto eu não escrevo um teatro realista, mas um teatro do real, no sentido em que o teatro realista é fabricado de uma maneira um pouco formatada: é um modelo com suas regras, a situação sentimental é conhecida, assim como a situação familiar e profissional. Um fala, outro responde. É o modelo da peça anglo-saxônica típica dos anos 60 que foi reproduzida e imitada por tanto tempo. Há exemplos magníficos, como em Pinter, o que não é necessariamente condenável, mas não é a forma que eu adotei. Estou cada vez mais evitando este tipo de realismo. Por outro lado não me privo de me apropriar do real através dos fatos do mundo pela via dos jornais. Em última instancia, todas minhas peças estão articuladas ao redor dos incidentes sociais, dos faits divers, mesmo que eles se tornem invisíveis ao final. Para mim, o combustível primordial é o fait divers, já que trata-se de uma história universal, que diz respeito a todo mundo. Eu não dato, não situo, mas tento fazer algo arcaico e universal. Dessa maneira, mesmo na minha peça sobre Ovídio, não há referencia à Grécia ou a Atenas, tudo permanece fora do tempo, é como no poema. Finalmente me aproximo de um conceito poético qual seja o de guardar a violência do fato real, porém de inseri-lo num dispositivo que seria mais próximo da ode, da canção, do ritornello, do poema. Ou seja, o intemporal fora do tempo e fora do lugar. Tudo isso se articula em torno do real, do jornal, mas graças ao seu formato há um outro tipo de entendimento ${ }^{11}$.

\section{As peças dos anos 90 e a passagem ao minimalismo}

Durante este período, um interesse evidente pelo fragmentário ou o descontínuo emerge nas minhas peças. Essas peças "fragmentos" seriam concebidas como uma série de quadros unidos por temas, por um périplo. Os fragmentos ou melhor os segmentos, que podemos chamar igualmente de vinhetas, são orquestrados como afrescos ou miniaturas, dentro dos quais cada uma das vinhetas conta uma parte da historia. Consequentemente, quando as totalizamos, temos a historia completa, mas entre os quadros 1 e 2 o tempo passou e isso não levamos em conta. É essa descontinuidade que me interessa. Eu aprecio as pinturas da alta Idade Media e princípios da Renascença: me sinto tocado por esses chapados, essas figuras eternas e arquetípicas que fazem sentido e têm energia; me sensibilizo por seu conteúdo dramático ou

\footnotetext{
${ }^{11}$ Ver o artigo de Michel Corvin, « Chez Minyana c'est la forme qui fait sens », in M. Corvin (dir.), Philippe Minyana ou la Parole visible, Paris, Éditions théâtrales, 2001, p. 9-26.
} 
grotesco. Gosto de percorrer os dois aspectos: a "farsa' e o drama ou o fúnebre e o grotesco. Esses dois matizes combinam entre si e fabricam o real, provocam o efeito de parecer real.

Para retornar à definição da figura teatral, pode-se dizer que sabemos pouco a seu respeito. Não sabemos o que ela diz, no momento em que está na cena. Consequentemente, a figura é provisória no teatro, ao passo que a personagem não. Por exemplo, em Hedda Gabler temos a personagem do começo ao fim da peça, em um continuum. Em algumas de minhas peças como La Maison des morts ${ }^{12}$, reencontramos esse processo: o espectador segue o percurso de uma mulher, chamada $\mathrm{A}$ Mulher de tranças (La femme à la natte), que não possui nome. A Mulher de tranças remete à figura teatral, mas também à personagem. Nós a seguimos, com efeito, ao longo de diferentes idades de sua vida: ela faz a faxina, ela tem um filho, ela o mata. Dessa maneira, o espectador dispõe em estações, como nos afrescos ou nas miniaturas, os momentos fortes de uma personagem. Extraímos disso a acme, ou seja, o clímax, mas não revelamos tudo. É isto que faz a diferença com a personagem, não há continuum mas as cenas singulares e decisivas nos são dadas.

Escrevi em 2006 a versão cênica de La Maison des morts ${ }^{13}$. Eu havia aceitado seguir a proposta do encenador Robert Cantarella ${ }^{14}$. Foi-me solicitado, como se trata de uma peça de interiores, de uma peça íntima (e não intimista, porque ela acontece em lugares íntimos como os salões e os quartos), acrescentar pequenas frases que falassem do exterior ${ }^{15}$. Tratava-se então de fazer um espetáculo "total" onde seria possível olhar, ouvir, ler e sentir. Isso pareceu as vezes complicado para certos espectadores e para outros, bem ao contrario, completamente envolvente. Gosto muito desse laconismo, da brevidade dessas frases que acrescentei e que adquirem a densidade do haiku. Sou fascinado por essa poesia japonesa e meu projeto de escrita tem o mesmo caráter: desembaraçar ao máximo um pensamento para extrair o cerne substantivo, encontrar a palavra certa, a palavra verdadeira. Isso obriga a uma economia. Encontramos esse mesmo processo na decoração, no design ou na arquitetura. Houve uma moda do minimalismo nos anos 80 , moda que persiste aliás. Seria preciso um sociólogo que fizesse a ligação entre o gesto artístico e a época. Existe certamente um laço que não percebemos ainda ou que não houve tempo para decodificá-lo.

\section{As peças dos anos 2000: um mergulho no surreal}

Houve uma mudança, uma ruptura: me cansei de escrever "A Mulher de tranças", "O Homem de preto", "O Homenzinho gordo". O laboratório de escrita estando ainda aberto, fez-me voltar aos nomes próprios, a nomes próprios um pouco singulares. No entanto, os nomes usados não são os nomes familiares: há o exemplo de

\footnotetext{
12 Philippe Minyana, La Maison des morts, Paris, Éditions théâtrales, 1996. 13 Philippe Minyana, La Maison des morts. Version scénique, Paris, Éditions théâtrales / Théâtre du Vieux-Colombier, 2006.

${ }^{14}$ A peça foi encenada em fevereiro de 2006 no Teatro do Vieux-Colombier, a segunda sala da Comédie-Française. Pode-se ler a análise do espetáculo feita por Fabienne Darge: « Philippe Minyana traque l'étrangeté dans la banalité du
}

quotidien », Le Monde, 10 février 2006.

15 Os textos eram na ocasião, projetados sobre uma tela e constituíam-se fora do quadro de cena. Philippe Minyana, Histoire de Roberta, Paris, Éditions théâtrales, 2006. 
Roberta, em Histoire de Roberta ${ }^{16}$, Émeline e Ruby na pequena peça breve que escrevi para a Commedie Française, e em Voilà encontramos Betty, Ruth e Nelly. Curiosamente são nomes anglo-saxões que aparecem. Esse retorno ao nome no meu projeto de escrita é acompanhado do desejo de viajem, de sonho. Isto aporta também uma nota de exotismo, de extravagância. Ruth é também um nome eterno, bíblico. A escolha do nome nas minhas peças está sempre ligada à atriz para quem eu escrevo, com o projeto. Há muitos parâmetros a serem levados em consideração.

Desde de 1995 eu incluo também muitas didascálias nas minhas peças e isso corresponde à tentativa de ultrapassar o formato da peça de teatro. Há este desejo de acompanhar a figura falante no seu cenário: saber onde ela fala, e o que ela faz enquanto fala. São os sintomas da palavra, como se coçar, se assoar, espirrar, tossir, que podem aparecer nas didascálias de muitas de minhas peças. Ultimamente, na peça De ma forêt profonde, o mato fala, a floresta fala. Ultrapassei aqui o limite da peça de teatro do real para adentrar no surreal, no maravilhoso, no imprevisto. Desde que escrevo, há trinta anos, abro a cada vez uma nova porta. Alem disso, sou eternamente um leitor cativo: passo a metade da minha vida lendo. A literatura, os nomes, os clímax, os romances oriundos da Noruega, da Suécia, do Japão me apaixonam. Contar uma história é uma verdadeira viagem. A questão que me parece a mais importante é como contar essa história e poder mudar o formato da narrativa.

Interessa-me extremamente também a produção dos autores contemporâneos. Existe, por exemplo, toda uma nova geração de jovens autores que emergem, bem variados, como o coletivo Lumière d'aout, ou como Ronan Cheneau. De uma maneira geral, o computador tem um lugar importante. Observa-se uma perda da forma teatral, não sei se isso é muito consciente. Não sei se isso vem de nossas memórias porque os jovens dizem que não possuem memória, que não tem pais, que eles não imitam ninguém. Eles são muito prolíficos, têm necessidade de contar o seu mundo, o mundo no qual desembarcaram. Eles estão bem ancorados na realidade de 2008 ao falar da televisão, dos ministros, do presidente da República, dos apresentadores, dos cantores, enquanto que eu me distancio com as florestas, as clareiras, eu estou na minha Idade Media. Esses jovens autores escrevem peças extremamente datadas, no sentido em que se apegam a realidades precisas. Alguns podem até dizer com certa malicia que se trata de peças descartáveis porque eles não querem entrar para a História, eles têm uma urgência, ou são íntimos de atores ou diretores... Mas eu acho que há uma bela energia nisso, um desejo de dizer. Esses jovens autores têm necessidade de proferir, de tornar precisos seus pensamentos graças à língua, e isso é importante.

Recebido em: 20/12/2014

Aprovado em: 30/05/2015

${ }^{16}$ Philippe Minyana, Histoire de Roberta, Paris, Éditions théâtrales, 2006. 